This is the Accepted Version of Burrell, Jenna and Oreglia, Elisa (2015) 'The myth of market price information: mobile phones and application of economic knowledge in ICTD' Economy and Society, $44(2)$ 271-292. Please refer to final article published by Taylor \& Francis when citing, available at:

http://www.tandfonline.com/doi/abs/10.1080/03085147.2015.1013742

Accepted Version downloaded from SOAS Research Online: http://eprints.soas.ac.uk/21827/

\title{
The Myth of Market Price Information: Mobile Phones and Epistemology in ICTD
}

Jenna Burrell, School of Information, UC Berkeley | jenna@ischool.berkeley.edu Elisa Oreglia, SOAS, University of London | eo6@soas.ac.uk

\begin{abstract}
The notion that farmers use mobile phones to acquire market price information has become a kind of shorthand for the potential of this technology to empower rural, low-income populations in the Global South. We argue that the envisioned consequences of 'market price information' to market efficiency with benefits at all income levels is a kind of myth, one frequently promulgated in the publications of aid agencies like the World Bank, in the project reports of NGOs, and by mass media outlets such as the Economist, but also as the subject of serious discussion among scholars. We show that 'market price information' has become a kind of boundary object recast across the expert cultures of economics, computer science, policy work, and development expertise. We draw from our ethnographic work (among rural agriculturalists in China and Uganda) to offer four alternatives to this myth.
\end{abstract}

Keywords: epistemology; mobile phones; China; Uganda; markets; agriculture 


\section{The Myth of Market Price Information: Mobile Phones and Epistemology in ICTD}

The mobile phone as a platform for the dissemination of information, and in particular market prices, has become a shorthand for the transformative possibilities of information in general for low-income, rural populations in the Global South. This new variant of economic development thinking after the decline of capital fundamentalism (Evans 2005) places mobile phones and other network infrastructures in a critical role, hastening an end to a state of presumed 'information scarcity' in remote regions. Such thinking is gaining influence in the domains of development policy and practice. In this article, we seek to gain specificity about the role of information in the emerging field of information and communication technologies and development (ICTD ${ }^{1}$ ), which brings together academic researchers and practitioners.

Our critique focuses on 'market price' as a particular type of information. We consider the translation of 'market prices' from neoclassical economic model, to ICTD truism, to application in technological system building. 'Information' in this process of translation is reified: it comes to be understood as a real and separable substance and is treated as existing in the world in the same way as the isolated variable in the economic model. It is imagined as unproblematically extractable, in particular, from the relationships between actors who exchange it. Yet, information is also understood to escape conventional material constraints. It may traverse digital networks at the speed of light and be costlessly reproduced. The characterization of information as a kind of substanceless-substance, which offers a practically cost-free way to enhance the incomes of the poor (i.e. by recapturing profits lost to market inefficiencies), explains some of its appeal to narratives of poverty-alleviation.

We give particular attention in our analysis to Market Information Systems (MIS) which are designed to collect and distribute 'market price information' impersonally. Recent evaluations show a disappointing lack of impact of MIS (Fafchamps and Minten 2012). Such negative evaluations suggest that questions could be asked about how economic knowledge is incorporated into technological system building and what understanding of the decision-making processes of farmers they assume and embed. We arrive at a plausible explanation for farmers' lack of interest in MIS through methods that ascertain as directly as possible the decision-making practices of rural agriculturalists. Such an approach draws attention to counter-narratives that are unavailable from within the conceptual and epistemological frameworks of the econometric studies and economic models that have been most influential to the thinking on market prices (and their scarcity) in ICTD and in the broader field of international development work.

In describing the emergence of this particular bit of economic knowledge as a 'myth,' we are noting its circulation within elite, technocratic circles, as further

\footnotetext{
${ }^{1}$ For work that considers broader characterizations of ICTD's ideology see Mazzarella (2010)
} 
represented in broad strokes by the mass media, and fuelled by repetition and an increasing tone of factuality, conviction, and presumed breadth of applicability. An ongoing conversation at the intersection of economic sociology and STS questions the relationship between economics and economies, considers economics as performed - attending to the way its theories and ideas are composed materiallyand examines the role of a range of economic actors from experts to 'non-experts' (such as consumers) in this performance (Barry and Slater 2007; MacKenzie et al 2007). Perhaps a reflection of the success of modern (and particularly mathematical) thinking in economics in promoting itself as a resource for powerful real-world solutions, it is the case that non-economist in many domains of expertise come to find economic models compelling and seek to extract from them what may be actionable. What are we then to make of the plausible charge that failures in application (such as in MIS) derive not from the inadequacy of the model, but from the 'misapplication' or 'misinterpretation' of economic knowledge? Could the models themselves be held accountable for misinterpretation in relation to the way economist's claim real-world relevance and applicability? We examine this through the notion of the myth of market price information as a boundary object necessarily translated and recast across fields and approaches.

To illustrate a counter-narrative to the myth, we draw from our qualitative research on trade, livelihoods, and mobile phones among low- to medium-income rural fishermen and fish traders in Uganda, and farmers in Northern rural China. In Uganda, the study was carried out by the first author through two fieldwork stints in four villages (including two fishing villages) on general questions of mobile phone use in livelihood activities. A small and quite remote fishing village on Lake Kyoga was visited in November of 2007. A larger landing site where fish are sold locally as well as packaged in trucks for export was visited in July of 2008. In China, fieldwork was carried out by the second author in three villages in the provinces of Shandong and Hebei in 2010 and in the summer of 2011, as part of a larger project on the adoption of mobile phones and computers in the villages. In both cases, the data was gathered through semi-structured interviews covering the use of ICT and people's livelihoods, accompanied by participant observation and casual conversations with residents and traders.

As social scientists with an interpretivist approach, and specifically as ethnographers, we place central significance on the explanations of fishermen and farmers themselves, the meaning and motive they attach to their actions. What economists investigate as 'mechanisms' are referred to by sociologists and anthropologists as 'processes' or 'practices,' a term which emphasizes a stronger sense of agency in the work done by human actors (Knorr Cetina et al. 2001). Our own epistemological commitments lead us to emphasize closeness to the phenomenon (over indirect measurements), interlinkages (rather than isolated variables), and rich detail. Our ideal data is observational (overheard phone calls, activities unfolding in the marketplace, etc) complemented by interviews where interviewees are prompted to draw from their firsthand experience. Through this approach we looked broadly at how the phone was used in conjunction with trade along the supply chain-including farmers/fishermen, middlemen/wholesalers, and retailers. 
In interviews, when given the opportunity to describe their key decisionmaking points and general practices of marketing their goods, our informants consistently disclaimed any practice of acquiring market price information for the purpose of comparison between markets (by phone or other means) with a few rare exceptions. However, in Uganda, fishermen and fish traders still described the mobile phone as critical to their trade activities. In China, by contrast, farmers found little use for the mobile phone in agricultural activities, even though mobile phones were widely available and actively used for other purposes. However, we suggest that the alternate behavior of these market actors is logical in the context of available resources and pressures related to their socio-economic circumstances and the social setting of village life that shape livelihood strategies.

\section{SECTION 1: BIRTH OF A MYTH}

\section{'Information' in Aid Policy and in the Mass Media}

We begin by outlining how this myth emerged, where it can be found, and in what forms it appears. How does information figure into the aid sectors evolving narratives about the causes of poverty and the pathways toward development? As scholars have noted, critiques of development are continually absorbed by the institutions facing such scrutiny and later resurface in reforms to the institutions' public face and self-description, though they may be far less radical than critics would hope for (Corbridge 2007). For example, accusations about the "democratic deficit" of the UN and other international organizations that seek to intervene in the lives of 'the poor' has been met with a number of adjustments: new objects for inclusion ("civil society") as well as new procedures, such as the much lauded "multi-stakeholder" approach. Likewise, efforts to soften a stark neoliberalism in development policy has led to the repackaging of scholarship on 'social capital' (Harriss 2001) and the championing of the 'informal economy' (Hart 2006) forwarding notions of the autonomy and agency of the populace and of 'the poor' in particular. Hetherington argues that 'information' in the context of development thinking is "productively vague" (Hetherington 2007). We likewise see the ambiguity of 'information' as part of how it endures the rise and fall of particular technological platforms for its dissemination.

Talk of 'information' in development reached an early point of culmination at the World Summit on the Information Society (WSIS), a UN event led by the International Telecommunications Union (ITU), launched in Geneva in 2003 and concluded in Tunis in 2005. In the WSIS outcome documents (2005), while information is considered relevant to many domains, ICTs are declared relevant to the economic specifically in their capacity to promote, enable, or accelerate economic growth through efficiency gains. Heatherington describes this as "information's most important promise" for development, "that it creates efficiency and therefore growth" (Heatherington 2007: 134). A notion of information as something globally abundant but maldistributed leads to characterizations of regional information-scarcity. This is apparent in a statement within the WSIS documents about unspecified "barriers to access" to information which, if 
eliminated, could benefit a whole range of activities among those currently "information poor" including their economic activities.

In the years following WSIS, the broad category of ICT and the general notion of information has been resituated, keeping pace with subsequent waves of technological change and diffusion that were not fully anticipated in the 2003-2005 time period. The mobile phone, given its near ubiquity in remote and rural regions of the Global South, is the current platform attached with great promise to alleviate poverty. Recent publications of relevance from major international aid organizations offer information-scarcity (often in a loosely quantified sense) as a baseline state that the mobile phone in particular is poised to mitigate. The ITU 2011 report on least developed countries (LDCs) argues that "People need information in order to function. The lack of it, particularly the lack of information about issues that directly affect your own life, is profoundly disabling and alienating.... LDCs, as states as well as their citizens, typically have fewer sources of information and fewer functioning links for the exchange of information than other countries" (ITU 2011). A World Bank 2012 report devoted entirely to the new reality of mobile phones and their potential for effecting 'development,' considers market price in particular as a type of actionable information. It states, "before the expansion of mobile networks, agricultural producers were often unaware of these prices and had to rely on information from traders and agents to determine whether, when, where, or for how much to sell their crops" (pg. 33). Like the ITU report, the World Bank report uses the framing of information-absence, but more specifically information of consequence to economic activities, namely, market prices.

The nature of information-scarcity and the new possibilities for resolving it are sometimes argued through reference to its costless reproducibility. The origins of such a notion harken back to a discourse emerging prior to WSIS and both reflected in and influenced by scholars such as Manual Castells and his notion of the "space of flows" (Castells 2000). This argument was most clearly articulated by the Digital Opportunity Initiative (DOI), a "public-private partnership" launched at the $26^{\text {th }}$ G8 summit in Okinawa, which involved representatives of the ITU, OECD, and UNESCO. In the concluding report of the DOI a particular relationship was asserted between the substance of information and its capacity to level the playing field, specifically to overcome locational disadvantage:

"ICT fosters the dissemination of information and knowledge by separating content from its physical location. This flow of information is largely impervious to geographic boundaries-allowing remote communities to become integrated into global networks and making information, knowledge and culture accessible, in theory, to anyone... The 'digital' and 'virtual' nature of many ICT products and services allows for zero or declining marginal costs. Replication of content is virtually free regardless of its volume, and marginal costs for distribution and communication are near zero. As a result, ICT can radically reduce transaction costs." (Markle Foundation 2001) 
In this way the economics of information as a good are established. Its substancelessness transcends the more inexorable constraints of physical capital, and usefully sidesteps methods of addressing impoverishment that might be more politically unfavorable, such as through redistribution. Rather, information under the right arrangements is thought to uncover a hidden source of wealth by eradicating heretofore irresolvable inefficiencies within regional markets.

What is most often cited as the evidential basis of this narrative about market price information is economist Robert Jensen's study of mobile phones, price information, and market efficiency in the sardine fishing industry of north Kerala (Jensen 2007). However, specific citations are not uniformly employed in the publications of the major aid agencies and in mass media accounts where this idea frequently recurs. In the course of repetition, it can increasingly be said with conviction and vague generality that, "farmers in Africa are accessing pricing information through text messages" (World Bank 2012: 4). This example of what Latour and Woolgar (1986) describe as the "deletion of modalities," is an indication of an idea, concept, or relationship that has come to gain the status of uncontested fact. The notion of the use of mobile phones by farmers to check market prices is in widespread circulation as the quintessential success story, sometimes explicitly labeled as such, not only by development agencies, but also by the industry. A report on women in agriculture published by GSMA, the --- of the mobile operators, states that "mAgri services empower women with information. One woman who uses Tigo Kilimo's Agri VAS service said that she can "bargain for a fair share of the household's income" now that she is informed of the current market price for the produce her family harvests" (GSMA 2014: 27). Nelson Mattos, Google's head of Emerging Markets, stated during a radio broadcast on "M-Development: Enabling Economic Opportunity in Emerging Markets" that "there is [sic] definitely a lot of success stories. We all hear about farmers being able to access price of products and being able to increase their revenue because of that...." Thus the myth becomes actionable as rhetoric in support of fund-raising or of smoothing the road for corporate market expansion.

\section{'Market price information' as boundary object in the ICTD community}

The emerging field of ICTD, of which we are participants and members, brings into contact different types of experts and professionals (from academia, research institutes, NGOs, aid agencies, and the commercial sector) with different forms of institutional backing and warrant for their work. They share an interest in understanding how digital technologies may help to realize development outcomes, by whatever definition one might attach to 'development.' ICTD can itself be identified as a community but in a rather broad and loose sense. It is not contained by any one institution and while there are moments of co-location (if infrequent), none bring the entirety of the community together at one time; key contributors to its ideas and discourse do not all recognize or identify themselves as members.

Our concern is with the way ideas that become common reference points are understood and applied by diverse players. Problems arise, in part, from the multiple challenges of this field where members trained in different disciplinary traditions meet and attempt to draw upon one another's efforts. One challenge has 
to do with disciplinary values, i.e. what members of different fields consider to be the priorities in the pursuit of knowledge and practice (Burrell and Toyama 2009). A second is validity, i.e. what members of different fields and communities consider to be compelling evidence or a convincing argument. The third relates to communication and to the terminology, case studies, publications, etc. that become a kind of shorthand within a discipline, but that become distorted while moving between groups. By examining the particularly widespread notion that farmers use mobile phones to seek market price information, we seek to concretely specify some of the challenges that stem from the involvement of NGOs and commercial entities in ICTD, specifically in the building of market information systems that often draw from academic research for justification.

We suggest that 'market price information' has come to serve as a boundary object. A boundary object is, "both plastic enough to adapt to local needs and the constraints of the several parties employing them, yet robust enough to maintain a common identity across sites." (Star and Greisemer 1989, pp. 393). That is, boundary objects have a common representation between diverse groups (such as economists and computer scientists or academics and practitioners), but are "weakly structured in common use" (ib.). Subgroups of the broader community develop a deeper understanding of a boundary object, but it "cannot be translated in a satisfactory way into terms used by other groups, since it reflects a different way of acting in the world (a different ontology and epistemology)" (Bannon and Bodker 1997, pp. 4). Therein lies a problem, as boundary objects can potentially lead, "to serious problems caused by the loss of the interpretive context which goes with the representation or information" (ib.). When farmers are described by economists as acquiring market prices via mobile phone, this claim is embedded within assumptions that are clear, if implicit, to the members of the same epistemological tradition, who also understand the limitations of their models. However, this is interpreted by members of other epistemological traditions (computer scientists, engineers, designers) according to their own "ways of acting in the world," and, for example, translated into a set of user requirements or other short-hands that are meaningful within their community, but that do not capture enough of what is necessary to know about these 'farmers' in order to make their solutions 'work' in the way the economic model suggests they should.

\section{SECTION TWO: A COUNTER NARRATIVE}

Here we provide an alternative reading of the promise of better market price information by focusing on how fishermen and farmers themselves describe the role that prices play in their decision-making about trade, the role that mobile phones play (or do not) in acquiring price information, and how regulatory and political frameworks influence all business decisions. The examples and specific quotes we offer, while individual, are presented to characterize the general thrust of our broader conversations with research participants. In other words, these are not the odd exceptions, but rather common descriptions of trade practices that were recurrent in our respective sites.

Our empirical work points to four divergences between the larger 'myth' as circulating within ICTD and development work and the aid sector more broadly: (1) 
the notion that information critical to decision-making is scarce and actively sought after by farmers/fishermen/small traders in rural settings; (2) that in their key decision-making practices, market price is the most critical piece of information; (3) that improvements in market functioning that follow from the arrival of mobile phones necessarily stem from the acquisition of market price information; and conversely (4) that the provisioning of market prices defines mobile phones major impactful application in the context of rural trade activities.

Phone use diverged between our two field sites. In Uganda, we find value offered by the phone for market actors across a whole range of roles and activities. In China, smallhold farmers find value in mobile phones quite apart from business purposes. In both our sites, price information was often of little relevance in decision-making related to trade activities. This was by virtue of alternate priorities of rural agriculturalists or structural conditions that made prices non-negotiable. By discussing a number of these priorities and conditions, we wish to restore some attention to the broader practices of trade that have rendered the mobile phone indispensable according to market actors, but not in the ways most often emphasized by researchers, practitioners, and the press.

\section{(1) INFORMATION ON PRICES IS NOT NECESSARILY SCARCE}

The broader narrative of information-scarcity noted above was not met with a similar account by the inhabitants of the rural, agricultural regions we studied, who were generally not at all preoccupied with the search for a better 'price.' Scarcity of information on prices is highly dependent on location-not all rural areas in developing countries experience such drought. In China, for example, the going prices for crops are widely known:

"I know the prices of crops and all those agricultural news from television. Also, there is a government official who comes to the village and tells us, he is from the agricultural office in the town,"

says a farmer in his mid-50s in Shandong. In the three villages where the second author carried out fieldwork (one in Hebei, two in Shandong, both provinces in Northern China) information on prices, but also on agricultural techniques, on fertilizers, on diseases and on new crops, comes from sources such as television, radio, newspapers (for those few who read them), traders, neighbors, agricultural extension workers, the head of the village, etc. People find out prices from multiple sources, and then constantly double-check them in the course of casual conversations. Most of this information gathering and sharing is not based on written text, but rather on oral exchanges among people known in person - a neighbor - or for their official role - a trader, an agricultural extension worker. Prices, at least at this level of small commerce, are inextricably embedded within relationships among people.

Another middle-aged woman farmer in the Hebei village has had a computer for a couple of years, and goes online every day, but mostly for entertainment and to watch television. She says, "We don't need the computer for (agricultural information). The agricultural extension worker comes to the village for all that we 
need to know about farming." An older farmer in one of the Shandong villages has a mobile phone and receives a daily weather forecast SMS. He is aware of the opportunities offered by the Internet, but even more aware that a lot of information that he could find himself online already reaches him through the agricultural extension worker, "There is an agricultural extension worker, actually there is one in the county and one in the town, so we get the one from the town, he comes here to tell us about fertilizer, or pesticide and all that. So we don't need to find out this information, because he tells us." The Chinese agricultural extension worker brings not only information, but also 'meta-information' that help farmers place what he says in context. This farmer, echoed by others, points out that he knows the agricultural extension worker personally, therefore he can evaluate the information he receives. It is certainly not the case that it is all good, or impartial, or useful information. But by knowing who the agricultural extension worker is, how he works within the community, what kind of relationship he has with, for example, seed sellers, the farmer knows how to parse what he says, and understand it in context. All this context is lost when the same information is detached from the information provider (Oreglia, Liu \& Zhao 2011).

Fieldwork in Uganda pointed to similar matters of relational context and a concern with information source. Fishermen in these villages also spoke of the material resources they needed to make it possible to act on better information. A focus group with members of a remote fishing village on Lake Kyoga showed a relatively low level of interest in information relative to other needs and priorities. When participants were asked directly about what types of information they desired, they continually turned the discussion back around to assets and facilities that would improve their lives. This started with a problem of translation: there was no word in Luganda that directly translates to 'information' so the word for 'news' was used as the best substitute. For example when asked:

Interviewer: "if you want information [news] on fishing issues, the information you will be interested in, what will it be talking about?"

Fisherman: "For the information [news] I would be interested in is that the government has put in place a good way of fishing, like giving people new fishing nets..."

In other words, the fisherman, in light of regulations enforced by the government against the use of traditional fishing nets (due to overfishing), wanted 'information' that the government would be giving away the legal (and expensive) nets. He did not truly desire information - he knew the rules and how they affected him - but rather he sought tangible assets.

Adding further nuance to the issue of information in remote, rural communities and its perceived scarcity, the village chairman (also a fisherman) expressed a desire not simply for information, but for "advice." Speaking now of the use of mosquito nets (or lack thereof) in the village to prevent malaria, the chairman responded "you may be having the money [to buy a mosquito net], but if no one has encouraged or advised you to use the mosquito net you may not bother." What he 
drew attention to with this comment was the question of information source and of the quality of the relationship between what he envisioned as a kind of mentoring figure and the village community.

The examples of the Ugandan chairman's desire for 'advice' and the Chinese farmer's reliance on the agricultural extension worker contrast with the impersonal nature of 'information' as it is conceived in scholarship that explores its role as a catalyst for socio-economic development. The lack of a word for 'information' in the Luganda language is a reminder that the general enthusiasm surrounding information as a development salve is promoting a concept to social/cultural settings where it is simply not as salient. ${ }^{2}$

\section{(2) MARKET PRICES ARE OFTEN IRRELEVANT OR SUBORDINATE TO OTHER FACTORS IN TRADE RELATED DECISION-MAKING}

An abstracted view of the role of information in the market removes prices from the trade practices and relationships between trade partners in which they are embedded. Yet such relationships appear to be critical at the level of smallhold farmers and fishermen, perhaps more so than for more affluent agriculturalists. Price is often an important factor in decision-making, but it is also one of several variables embedded in specific local conditions. Existing business relationships, trust, attitude towards risk, and institutional rules and policies around the goods traded-these are all inputs for fishermen and farmers' final decisions on whether to sell or not, whom to sell to, what species to fish and what crops to grow, etc. Among our research participants, two factors took precedence over price in making sales decisions: long-term relationships with trade partners and individual attitudes towards risk.

\subsection{Long-term relationships with trade partners}

Among our research participants, an ability to act on 'information' was often tied to who was the source of this information and the trust in that person earned over a history of interactions. In 'new institutional economics' the need to trade with known and trusted trade partners is considered a particular adaptation within a certain institutional context, specifically one lacking structures for effectively enforcing contracts (Fafchamps 2004). Granovetter (1985) suggests more broadly that markets everywhere are embedded in social relations between specific individuals. He shows that the literature in economics tends to have either an undersocialized or an oversocialized view of human interaction, the first explaining every social institution in a functionalist mode as "the [most] efficient solution to certain economic problems" (Ib. 490), and the latter calling for a generalized

2 The contemporary notion of information goes back to the mathematical developments of "information theory" and the work of mathematician Claude Shannon. Frank Webster points to efforts to quantify growth in the amount of information as a reflection of the way definitions of information have come to dispense with information as containing semantic content. It is understood instead "as a physical element as much as is energy or matter." (Webster 2006). 
morality as an entrenched norm that guides social life and that explains the existence of trust in market transactions. Granovetter, on the other hand, highlights the fact that it is the "concrete personal relations and the obligations inherent in them" (Ib. 488) that are at the basis of the trust that prevents market actors from malfeasance.

In Uganda, the mobile phone, as a tool for building and maintaining a social network of 'concrete personal relations' in an industry of remote and distributed suppliers and buyers proved critical. On the problem of unreliable trade partners, one trader/middleman in the fish export business noted,

"Some other people can lie to you that they will give you cash immediately, you bring the fish, but then when you bring it, they disappoint you."

The significance of relationships was all the more evident on Lake Victoria where fishermen, by and large, took credit from the middlemen who bought up fish and transported it to the factories for export. Given these credit dependencies, fishermen (who had progressed in trade enough to own some assets such as a boat or nets) sold exclusively to the middleman to whom they were indebted, removing the possibility of comparing and making decisions on whom to sell to based on the best price. Moreover, beyond the way credit dependencies removed the possibility of price negotiation, for the lowest level fishermen working exclusively on salary, checking prices could even be a threat to their employment or even their freedom. Fishermen at this level own no assets and have no say over whom to sell the fish catch to or for how much. One such fisherman who also worked as a porter (another low-level, labor intensive jobs) commented on market prices,

"I leave it to the boss because if am caught he would throw [me] in jail, it would clearly indicate that I clearly want to operate behind his back."

He refers to those fishermen who, once outside the surveillance of their employer, will attempt to sell some portion of a fish catch. A woman who worked as a smoked fish seller in the fishing village on Lake Victoria in Uganda noted that the mobile phone was most critical for capturing supply. It was essential that she maintain her availability so that if her supplier called she could be there immediately to buy his fish before another smoked fish seller did. Characterizing her relationship to her supplier she said,

"I have been his customer for a long time I have been dealing with him for 3 years now... I buy from him at good price, I don't disturb him."

In other words, she makes transactions with her supplier as smooth and seamless as possible and does not even haggle over prices or call other suppliers to check their prices. She offered this as an explanation for why her supplier treated her with preference over other smoked fish sellers.

\subsection{Attitude Towards Risk}


Among rural agriculturalists, traders, and retailers at the low-income end of the spectrum, income predictability (an expression of their conservative attitude towards risk) often appeared to take precedence over a short-term focus on maximizing profits. This was the case with the smoked fish seller (above) who since separating from her husband seven years prior became her family's sole breadwinner. She was the one upon whom her children (and specifically their education) were totally reliant. She was explicit about the purpose to which her profits were put, as she said, "I am gaining some money which I use for the children's school fees." In both sites we have seen varying degrees of willingness to take on risk, and to diverge from the patterns of others (neighbors, etc) in order to realize a gain, often related especially to family composition and stage of life. This was also true among the Chinese participants, who were mostly middle-aged or elderly. In China, the average age of farmers is increasing (Huang 2012), which often means that farming serves as a combination of income generation and social security. Farmers do not have state pensions, so grow crops that can be both sold and eaten; their main concern is predictability. If there are emergencies, it is easier to rely on remittances from migrant children or find a casual job nearby:

"There isn't a big pressure to get a better income from the land, because almost everybody has income from work outside. I'd say for most families, half of the yearly income is from the land, half from other work... Also, my goal is not to grow my income or business, as long as things remain ok, that's all I need. The internet is useful for young people who want to improve and grow their business, not for old people like me. My children are all grown up and have good jobs, so I don't need much and don't have lots of worries. Until two years ago I also went out to work but now I don't. There's no need."

Prior to any decision-making about prices, both the Chinese farmers and the Ugandan fishermen had an initial decision to make about what crop to plant or what species to fish. These decisions were made in anticipation of price, but often in terms of how stable or predictable the price was likely to be for their harvest. Besides price fluctuations, other factors related to risk entered into this decision. For the fishermen, fishing the variety called Mukene (minnows) (as opposed to the larger Nile Perch and Tilapia fish for export) meant staying closer to shore and facing less exposure and danger (from storms or pirates) out on open water.

For the Chinese farmers, planting the same crops as their neighbors was another way of mitigating risk, as other farmers in the village provide a network of support for the individual. ${ }^{3}$ They share their knowledge of farming, sometimes

3 The majority of farmers in the areas where the second author did fieldwork grew the same crops: wheat and corn, typically planted one after the other, followed by peanuts, sweet potatoes, and some cotton. This is aligned with province-wide statistics on crops, although there is more variety in other districts. Shandong is renowned for its apples, grapes, and cherries, as well as its vegetables, but these tend to be cultivated by bigger commercial entities and be more integrated in wider markets [Vassilos, 2008]. Wheat and corn are the traditional crops of Northeast China. Their prices do not fluctuate much since 2006, when the government established a "minimum guarantee price" policy for wheat. This means that when the market price is lower than the minimum price fixed by the government, SINOGRAIN (the China Grain 
directly by giving suggestions, sometimes indirectly by starting to do a specific task such as using fertilizer in their field and thereby communicating to the others that it was time to do that work. They share risks, so if something happens to a crop, it's usually a common problem and perhaps someone will come up with a solution. It is important to note that this is not in any way a communal form of agriculture as in the collective farming of the pre-1980s reforms era, where the land was owned by the village, and each village had to grow crops according to the central government's planning, but rather a practical solution to distributing risks. The network of support represented by neighbors growing the same crop and experiencing the same issues disappears when a farmer decides to grow something different, and therefore doesn't have anyone to consult in case of troubles. For farmers who depend entirely on their crop for food and income, such a risk could potentially be ruinous, and one disastrous year would be enough to make them desist from such experimentation.

If the selling/buying behavior of farmers in China and the smoked fish seller in Uganda is seen as one discrete decision point, it might seem illogical. However the coherence of their reasoning is apparent when seen in the broader context of life events and opportunities that unveil over the course of a longer period, and that are shaped by past experience and current conditions of both the individual and the community.

\section{(3) IMPROVEMENTS IN MARKET EFFICIENCY REALIZED BY THE MOBILE PHONE MAY NOT STEM FROM THE BETTER CIRCULATION OF MARKET PRICES}

A constant refrain among rural mobile phone users is how, by using the mobile phone, they avoid wasted trips, as also noted in Overa (2005). The issue of 'wasted trips' though it certainly has to do with inconveniences and discomforts experienced by market actors, also has to do with market efficiency. The information that pertains to this work of avoiding wasted trips (and waste in general) was not specifically market prices. For example, a relatively affluent fisherman working on Lake Victoria, noted the value of his mobile phone for calling and requesting ice (key to preserving fish). He would call any of his contacts at the landing site and have them send out ice to him on the next boat. Ice, storm information, and equipment failure were all unpredictable factors. The trader first mentioned above, who bought fish for export spoke of a particular recent incident where just such a series of factors were in play (engine trouble, a storm) and a shipment of fish was saved from being dumped by the use of the mobile phone.

"After the coming of the phone, I remember one time the engine failed when we were supposed to arrive here at 4:00pm and if we didn't get in contact with people here, the truck would leave us. So we had to inform them about our problem and assure them

Reserve Corporation that is the implementation body for this policy) purchases farmers' grain at the minimum guaranteed price (Li et al 2011:97-98) This made crops like wheat very attractive for farmers who preferred to avoid risks: they planted what their neighbors were planting, they watered their fields, used pesticide or fertilizers, and started works like seeding and harvesting at the same time as the rest of the village. 
that we were coming and we arrive at almost 10:00am because of engine failure and the storm. But because we had informed them, they were here waiting for us. So the phone helped us so much."

This is not simply information exchange, but coordination work, specifically work to synchronize buyer and sellers (or fishermen and supplies) in time and space. Information of various sorts is part of this work, but the broader practice of coordination does not readily conform to the reification of information-asextractable-good. In Uganda, the information being passed around had to do with quantities of fish, availability of supplies (ice, fuel), location of vehicles and people, estimated time of arrival, sufficiency of cash for making payments, etc. Along the way reputational information was not necessarily explicitly communicated, but was nonetheless acquired through the process of arranging these transactions. This is reflected in the fish export trader's comment (as quoted above), "people can lie to you that they will give you cash immediately, you bring the fish but then when you bring it, they disappoint you." The converse situation bolsters the reputation of the one who came reliably with cash as they had promised.

Similarly, the head of the village near where Mr. Liu lived had a contact at a wheat mill, and would call him at harvest time to negotiate the sale of wheat directly, on behalf of most of the villagers. The price was usually slightly higher than what traders offered, and farmers trusted the head of the village to negotiate a good deal for everybody, because of his personal relationship with the mill buyer. The phone facilitated a relationship and the practical coordination aspects of it, both of which had been in place before the arrival of any kind of telephony.

The more direct evidence of these reported practices suggests other mechanisms that may be responsible for improvements in market efficiency. These improvements result not from market prices, but by what is imparted in the coordination work among trusted parties in order to avoid loss, waste, and delay.

\section{(4) OBTAINING MARKET PRICES IS OFTEN NOT THE MOST VALUED APPLICATION OF THE MOBILE PHONE IN TRADE}

Apart from coordination work, fishermen found that the mobile phone was useful-indeed, in some cases essential-for its most basic functionality: connecting two individuals across sometimes vast distances for synchronous, speech-based communication. The phone can help to establish and maintain one's reputation as a market actor, as noted above. Phone calls picked up immediately or made to communicate the status of a shipment contribute to one's reputation just as do successful face-to-face transactions. For some, this was considered absolutely critical to being able to participate in trade at all, as the smoked fish seller notes: "If you do not have a phone, you can't get these kinds of jobs." Phone calls did not simply transfer information, but also communicated requests or commands-to 'send ice' or to 'meet the boat at a particular time and place' or commitments such as, 'I will come with cash.' These phone calls were speech acts that had some force. Looking at communicated speech in this way, it is helpful to distinguish between locutionary and illocutionary acts of speech. The former refers to what the speaker says specifically, the latter to the force of what is said and the intended effect on the 
listener, to drive the listener to specific actions (Austin 1960). Information communicated about price also entailed an indication (if not a firm commitment) that the buying party, by imparting a price, would be willing to buy at that price.

Uses of the mobile phone also differed quite substantially between roles in the fish supply chain. For frontline fishermen in Uganda who worked for salaries (and thus were not part of price negotiations), by far the most critical use of the phone was to seek rescue when an engine died, a storm struck, or the boat was attacked by pirates, as other studies have also found (Abraham 2007; Sreekumar 2011). For middlemen in the fish supply chain, the phone could be useful as a tool for doing surveillance and monitoring at a distance. The fish export trader, who was concerned that the fishermen who were indebted to him would sell some portion of the catch surreptitiously, used his widely dispersed social network, a product of a lifetime living and working in the area, to keep track of his debtors. The phone was critical to this as he noted, "when you come to me, I first find out who you are, your family and about your work so even if he [the fisherman] got lost, I would locate him." To locate this debtor he called around to other villages to find fishermen who had disappeared and to get reports of whether fish had been sold without his knowledge.

This is not to say that 'pure' information sources are never valuable. In rural China, by far the most successful use of mobile phones in farming has been the weather forecast report delivered daily via SMS. The subscription costs about RMB3 per month (\$0.42), and many farmers subscribed to it, even those who had a hard time reading the screen or finding the message itself. The forecast helps decrease short-term uncertainty, and augments existing sources. As the first farmer we discussed summarizes:

"First I watch the national weather report on television; then I watch the local one; then I compare them with the weather forecast I get on my mobile. Then I analyze this information and come up with my forecast, and it's 70\% reliable."

The weather forecast is something immediately actionable, and it fits the farmer's existing routine to assess the weather: listening to news from multiple sources. It is also something that complements existing sources of information, which are not specific enough to his area, nor accurate enough.

This fourth and final 'myth' about market price information illustrates the way an investment in a particular scholarly conceptualization can obscure comprehension of the full range of ground-level priorities. When information was sought out in our fieldsites, it covered an array of topics that went well beyond market prices to include status updates about shipments and transactions in process, information about trade partners that might reshape reputation assessments, and weather predictions. The phone was a platform for relational work, for communication, for sparking action. The information exchanged was inseparably intertwined with this work.

\section{Explaining the Failure of Market Information Services (MIS)}




\section{Draft - Do Not Cite without Authors' Permission}

The first generation of MIS for agriculture in developing countries began in the 1980s, and focused exclusively on prices, a single crop, nation-wide coverage and distribution of information through radio broadcast. The diffusion of a new generation of ICT in the late 1990s brought about a second, much more diverse generation of MIS, which distribute information through different channels, focus on different crops, can be much more localized than the previous generation's, and propose services that go beyond market prices (David-Benz et al, 2011). Starting from the late 2000s, the number of MIS and in general agricultural applications for mobile phones has increased significantly ${ }^{4}$, with a wide variety of services on offer (Aker, 2011). Evaluations of the impact of such systems are just beginning, but some studies have shown poor rates of adoption, and a limited impact of SMS-based market price information services on market efficiency (Fafchamps and Minten 2012; Camacho and Conover 2011).

Drawing from our consideration of the decision-making processes of rural agriculturalists, one explanation for the failure of MIS is that this 'information' likely loses its usefulness once extracted from actual trade relationships and presented impersonally (i.e. as an SMS message) apart from any commitment from a buyer to pay the reported price. In fact, the canonical study often cited as proof of market efficiency through price information considered person-to-person voice-based phone calls (Jensen 2007). The representation of this as impersonal information exchange is a consequence of abstraction in the model. The extra details of the conversation are excluded from the economists' model in order to communicate new insights parsimoniously, according to discipline-specific practices of knowledge building. Yet in the application of such findings in MIS, person-to-person phone calls in which more than just market prices were likely communicated become SMS messages in which the personal and business relationships between callers are dispensed with.

A second explanation for the failure of MIS, we suggest, stems from the encoding of market actors and their decision-making practices in system designs based on epistemological assumptions (of the utility maximizing market actor of neoclassical economics) that are supported by indirect evidence from econometric studies (i.e. of shifts in price in the market as opposed to direct apprehension of actual phone use). However, even this indirect evidence shows that this applies only to middle-income or affluent agriculturalists. In the wider circulation of 'market price information' as boundary object, and through the process of "deletion of modalities" (Latour and Woolgar 1986) this model of decision-making comes to characterize the category of 'farmers' or 'fishermen' as a whole, and is assumed to

\footnotetext{
${ }^{4}$ An effort by our summer intern Luisa Beck to locate as many of these market-related services as could be found turned up 216 total projects, 72 of which provided market price information. The majority (50) offer market information via SMS. Most of these (34) offered such information only in text format. ANONYMIZED The most well-known and widely scaled services in this space are a mixture of aid agency and private sector efforts and include Esoko (formerly TradeNet), Reuters Market Light, Mistowa (a project of USAID), and Nokia Life Tools.
} 


\section{Draft - Do Not Cite without Authors' Permission}

be inclusive of those at the lowest-income levels as well.

Jensen's study on the impact of mobile phones in Kerala's fishing industry distinguishes between small and large-scale fishing units and finds that all units realized measurable higher profits (on average) after the arrival of the mobile phone, but it was the large-scale units only who used the mobile phones directly whereas smaller ones (and their poorer fishermen) gained indirectly from "spillover gains." However, in the circulation of 'market price information' as povertyalleviating across different fields of interest and practice in ICTD, these important distinctions have often been stripped away and lost.

In the ICTD field both researchers and practitioners are generally interested in the way users in lower socio-economic strata might benefit directly from the phone and other ICTs. We find the smaller-scale market actors-low-income farmers and fishermen who own few or no assets-have less ability to act on better information about market price related to a reasonable reluctance to take on risk as well as a lack of resources, such as not having enough capital to fund travel to distant markets. Further exclusions follow from the reliance on SMS-based market information services which introduce literacy barriers that were not there to begin with, in the prior voice-based modes of information exchange. They consequently block access to lower-income groups (often the least educated) even though these farmers may be the ones purportedly targeted by such a service.

Proposing an alternative way of building MIS is beyond the scope of this paper, but we conclude by noting that as the first wave of mobile- and web-based MIS begins to be assessed, there is a consensus that prices alone are not sufficient, and that a 'prices plus' approach is the preferable solution, where the plus consists of other types of localized information (e.g. a recent Mobile for Development webinar, GSMA 2012). We have shown that taking a different perspective on market prices of small agriculturalists results necessarily in a different type of MIS that are based on the political economy and social organization of local markets, rather than on abstract economic principles.

\section{Conclusion}

By examining the role market prices play (and the role they do not play) in the decision-making of rural agriculturalists, we have contributed a critical view on the rise of 'information' in development policy and practice, how its relationship to the market is described, and consequently how its capacity for poverty alleviation is imagined and enacted, especially as embedded in the code and configurations of market information systems. This idea of 'information' treats it as something that can circulate intact with its utility to end users unaltered. The declining expense of infrastructure building and the accompanying spread of mobile phones into rural and remote regions is considered an important step toward overcoming a state of information scarcity. Such regions are newly diagnosed with this affliction and information comes to be positioned as a powerful potential salve for poverty.

As an alternative to this line of thinking, we presented findings from two field sites and their populations, both of which contributed similar insights toward an alternative understanding of the role of market prices and information delivery via mobile phone. However, the livelihood strategies and trade practices we observed in 


\section{Draft - Do Not Cite without Authors' Permission}

these two sites were organized in different ways. In China, the sharing of risk was a key consideration in deciding what to plant and in selling the resulting crops. Farmers generally did not seek a competitive edge by differentiating from other farmers, but rather followed along with their rural neighbors as a way of buffeting themselves against the vagaries of weather, crop pests, and the global economy. In Uganda, the nature of fishing entailed travel onto the lake and away from the landing site for a few days at a time. This plus the perishability of this commodity yielded a special emphasis on the need for efficient coordination across time and space and between different roles in the fishing industry in order to supply ice and fuel, seek rescue, and predict arrival times among other forms of contingency handling.

The comparison and critique presented in this article follows a wellestablished mode in economic sociology, contrasting a parsimonious and abstracted model in economics to the ethnographic particularities of sites that diverge from the expectations set by the model. We make this comparison, not simply to provide yet another account of economic 'misrepresentation' of the 'real' world, but rather as a way to surface the messiness and confusion of an economic idea in actual circulation. In the notion of the 'boundary object' we indicate the impossibility of a perfect translation across disciplines and between model and practice. Economists might justly claim misinterpretation and misapplication in the deformations of economic knowledge as it travels and is employed by non-economists, but at the same time this allows the field of economics to seize a victory of influence while sidestepping accountability.

We wish to make a further point that where an attempt is made to apply the model and such an application fails (as is evident from some of the emerging evaluations of MIS) it is exceedingly difficult to arrive at an explanation based on the world selectively represented within the model. If we take the perspective of prices, to the exclusion of all else, then as small-scale agriculturalists are put in a position to easily discover them, one would expect as a result that they will get a better price and general welfare (as measured by income) will increase. If this does not happen, innumerable additional elements in the context that might explain why agriculturalists are still not getting better prices, remain absent from the picture presented by the model. In this way, an intelligible counter-narrative is suppressed and the predominance of price is naturalized into the way that the market works. Furthermore, groups outside the circuit of a performed and reified economic knowledge (such as the rural agriculturalists whose practices fail to conform to the myth) come to appear irrational.

As we have demonstrated in this article, the counter-narrative about 'market prices' can be heard by involving these agriculturalists directly in conversations about how they make decisions. Thus our critique is, at a fundamental level, also a call for methodological diversity both in ICTD and in development policy and practice. Narrow definitions of empiricism within certain currently influential strains of development economics prevent the methods we have utilized here from 
being routinely incorporated into the way knowledge about poverty is generated ${ }^{5}$. Yet, it is reasonable to question the coherence of categories and concepts when the applications, systems, or policies that they give rise to fail. Absent this consideration, we illustrate the creation of an echo-chamber yielding and reinforcing a compelling myth, here the notion that 'farmers using mobile phones to get market prices.'

\section{Acknowledgements}

Removed for anonymization

\section{Bibliography}

Abraham, R. (2007). Mobile Phones and Economic Development: Evidence from the Fishing Industry in India. Information Technologies and International Development, 4(1), 5-17.

Aker, J. (2011). Dial "A" for Agriculture: A Review of Information and Communication Technologies for Agricultural Extension in Developing Countries. CGD Working Paper 269. Washington, D.C.: Center for Global Development.

Austin, J. L. (1960). How to Do Things With Words. Oxford: Clarendon Press.

Bannon, L., \& Bødker, S. (1997). Constructing Common Information Spaces. Proceedings of the fifth conference on European Conference on ComputerSupported Cooperative Work, 81-96.

Barry, A., \& Slater, D. (Eds.). (2005). The Technological Economy. London: Routledge.

Burrell, J., \& Toyama, K. (2009). What Constitutes Good ICTD Research? Information Technologies and International Development, 5(3), 82-94.

Camacho, A., \& Conover, E. (2011). The Impact of Receiving SMS Price and Weather Information in Colombia's Agricultural Sector. Working Paper.

Castells, M. (1996). The Rise of the Network Society (Vol. 1). Oxford: Blackwell Publishing.

Corbridge, S. (2007). The (im)possibility of development studies. Economy and Society, 36(2), 179-211.

\footnotetext{
${ }^{5}$ Economist Dani Rodrik, for example, in a critique of the use of randomized controlled trials (RCTs) to evaluate development interventions advocates for unstructured interviews to take stock of "local knowledge" to arrive at explanations and to inspire new solutions (Rodrik 2008).
} 
David-Benz, H., et al. (2011) Market Information Systems: Using Information to Improve Farmers' Market Power and Farmers Organizations' Voice. Agrinatura, Policy Brief No. 7.

Evans, P. (2005). The Challenges of the "Institutional Turn": New Interdisciplinary Opportunities in Development Theory. In V. Nee \& R. Swedberg (Eds.), The Economic Sociology of Capitalist Institutions (pp. 90-116). Princeton, NJ: Princeton University Press.

Fafchamps, M., \& Minten, B. (2012). Impact of SMS-Based Agricultural Information on Indian Farmers. The World Bank Economic Review, 2(27), 1-32.

Fafchamps, M. (2004). Market Institutions in Sub-Saharan Africa: Theory and Evidence. Cambridge, MA: The MIT Press.

Granovetter, M. (1985). Economic Action and Social Structure: The Problem of Embeddedness. The American Journal of Sociology, 91(3), 481-510.

GSMA (2012). Mobile Market Information Systems for Farmers: Requirements for Success. GSMA Mobile for Development webinar. http://www.gsma.com/mobilefordevelopment/magri-webinar-mobilemarket-information-systems-for-farmers-requirements-for-success/

GSMA mWomen and GSMA mAgri Programmes (2014). Women in Agriculture: A Toolkit for Mobile Services Practitioners. http://www.gsma.com/mobilefordevelopment/wpcontent/uploads/2014/06/Women_in_Agriculturea_Toolkit_for_Mobile_Services_Practitioners.pdf

Harriss, J. (2001). Depoliticizing Development: the World Bank and Social Capital. London: Anthem Press.

Hart, K. (2006). Bureaucratic Form and the Informal Economy. In B. GuhaKhasnobis, R. Kanbur, \& E. Ostrom (Eds.), Linking the Formal and Informal Economy: Concepts and Policies (pp. 21-35). Oxford: Oxford University Press.

Hetherington, K. (2012). Promising information: democracy, development, and the remapping of Latin America, 37-41.

Huang, Y. (2012). From the "feminization of agriculture" to the "ageing of farming populations": Demographic transition and farming in a central Chinese village. Local Economy, 27(1), 19-32.

International Telecommunication Union (2011). The Role of ICT in Advancing Growth in Least Developed Countries: Trends, Challenges, and Opportunities. Available at http://www.itu.int/pub/D-LDC-ICTLDC.2011-2011. 
Jensen, R. (2007). The Digital Provide: Information (Technology), Market Performance, and Welfare in the South Indian Fisheries Sector. The Quarterly Journal of Economics, 122(3), 879-924.

Knorr-Cetina, K., Schatzki, T., \& Savigny, E. V. (Eds.). (2001). The Practice Turn in Contemporary Theory. London: Routledge.

Latour, B., \& Woolgar, S. (1986). Laboratory Life: the construction of scientific facts. Princeton, NJ: Princeton University Press.

Li, X., Wang, S., \& Jia, Y. (2011). Grain Market and Policy in China. In B. Alpermann (Ed.), Politics and Markets in Rural China (pp. 89-105). Routledge.

MacKenzie, D., Muniesa, F., \& Siu, L. (2007). Do Economists Make Markets? On the Performativity of Economics. Princeton, NJ: Princeton University Press.

Markle Foundation (2001). Creating a Development Dynamic: Final Report of the Digital Opportunity Initiative. Available at http://www.markle.org/sites/default/files/doifinalreport.pdf

Mazzarella, W. (2010). Beautiful balloon: The digital divide and the charisma of new media in India. American Ethnologist, 37, 783-804.

Oreglia, E., Liu, Y., \& Zhao, W. (2011). Designing for Emerging Rural Users: Experiences from China. Proceedings of the SIGCHI Conference on Human Factors in Computing Systems, 1433-1436.

Overa, R. (2005). Networks, Distance, and Trust: Telecommunications Development and Changing Trading Practices in Ghana. World Development, 34(7), 13011315. doi:10.1016/j.worlddev.2005.11.015

Rodrik, D. (2008). The new development economics: we shall experiment, but how shall we learn? Cambridge, MA. Retrieved from http://papers.ssrn.com/sol3/papers.cfm?abstract_id=1296115

Sreekumar, T. T. (2011). Mobile Phones and the Cultural Ecology of Fishing in Kerala, India. The Information Society, 27(3), 172-180. doi:10.1080/01972243.2011.566756

Star, S. L., \& Griesemer, J. R. (1989). Institutional Ecology, “Translations” and Boundary Objects: Amateurs and Professionals in Berkeley's Museum of Vertebrate Zoology, 1907-39. Social Studies of Science, 19(3), 387-420.

Vassilos, R., Sanchez, J., \& Beckman, C. (2008). An In-depth Look at the Fruit and Vegetable Markets in Shandong Province. USDA Foreign Agricultural Service, Global Agriculture Information Network, 1-12. 
Webster, F. (2006). Theories of the Information Society (Third Ed.). London and New York: Routledge.

World Bank (2012). Information and Communications for Development 2012:

Maximizing Mobile. Available at http://go.worldbank.org/0J2CTQTYP0.

WSIS. (2005). WSIS Outcome Documents. Geneva: International Telecommunication Union. 